\title{
Fluoride and oxidative stress in postmenopausal women
}

\author{
Parinita Kataraki ${ }^{1}$, Pragna $\mathrm{Rao}^{2}$. \\ ${ }^{1}$ Assistant Professor, Department of Biochemistry Shri B M Patil Medical College \& Research \\ Centre, Bijapur, Karnataka, India- 586103 \\ ${ }^{2}$ Professor and HOD, Department of Biochemistry Kasturba Medical College, Manipal, Manipal \\ University, Karnataka, India- 576104
}

\begin{abstract}
Fluorosis is a serious public health problem in many parts of the world where drinking water contains more than 1 ppm of fluoride. Higher intake of fluoride will result in dental and skeletal fluorosis and affect collagen synthesis and bone mineralization. Approximately $99 \%$ of the body burden of fluoride is associated with calcified tissues. The fluoride concentration in bone is not uniform. Fluoride concentration in bone is not uniform and higher fluoride levels in the body are associated with calcified tissues.

The study was conducted on 100 subjects with their consent which consisted of control group of 50 nonpregnant women in their reproductive age group. Study group consisted of 50 women who had attained menopause either naturally or surgically, all residing in the endemic fluorotic area of Nalgonda district, Andhra Pradesh, India. $5 \mathrm{ml}$ of venous blood was collected from both the groups.

Serum fluoride levels $(0.68 \pm 0.39$; $p<0.005)$ was statically significant when compared to the controls $(0.45 \pm$ 0.28). Serum malondialdehyde, a lipid peroxidation product, was measured as an indicator of oxidative stress induced by fluorosis, was statistically significant $(287.86 \pm 49.79 ; p<0.001)$.
\end{abstract}

Keywords—Fluorosis, post menopausal women, malondialdehyde, oxidative stress, osteoporosis

\section{INTRODUCTION}

Oxidative stress is a biochemical disequilibrium propitiated by excessive production of free radicals and reactive oxygen species, which provoke oxidative damage to biomolecules and which cannot be counteracted by antioxidative systems. This biochemical alteration has been linked with ageing and more of 100 chronic degenerative diseases, among which osteoporosis is found. It has been demonstrated recently that free radicals intervene in bone resorption, promoting osteoclastic differentiation in such a manner that bone resorption is increased with oxidative stress. ${ }^{1}$

Reactive oxygen species initiate the peroxidation of membrane lipids and produce malondialdehyde as one of the end products ${ }^{2}$ which is one of the most frequently used indicator of lipid peroxidation, the levels of which indicate the oxidative stress. ${ }^{3}$

Fluorosis is a serious public health problem in many parts of the world where drinking water contains more than $1 \mathrm{ppm}$ of fluoride. Higher concentration of fluoride are known to affect collagen synthesis and bone mineralization. ${ }^{4}$ Approximately $99 \%$ of the body burden of fluoride is associated with calcified tissues. The fluoride concentration in bone is not uniform. ${ }^{5}$

Increased production of reactive oxygen species and lipid peroxidation has been considered to play an important role in the pathogenesis of chronic fluoride toxicity. ${ }^{4}$

\section{MATERIALS AND METHODS}

50 postmenopausal women as patients and 50 non-pregnant women in their reproductive age group as controls, attending Orthopedics and Obstetrics and Gynaecology departments, KIMS, Narketpally, Nalgonda district, an endemic fluorotic area, Andra Pradesh, were inducted in the study.

2.1Inclusion criteria:

Women who had attained menopause either surgically or naturally were included in the patient group and women in their reproductive age group, who were non-pregnant were included in the control group. All the subjects were from surrounding villages of Nalgonda district.

2.2Exclusion criteria:

Women with liver disorders, alcoholism hyper / hypothyroidism and women on medication with vitamin $\mathrm{D}$, calcium and hormone replacement therapy were excluded from the study. 


\section{3collection of blood sample for analysis:}

$5 \mathrm{ml}$ of random venous blood was drawn from the out patients, into a sterile disposable syringe which was transferred into centrifuge tubes. The sample was centrifuged at 3000 rotations per minute for 10 minutes and the serum was collected from the centrifuge tubes.

\section{STATISTICAL ANALYSIS}

The statistical analysis was performed using SPSS software 11 version. The descriptive results are expressed as mean and standard deviation. Significance of difference between the patient and control groups observed is assessed by using the student $t$ test. The $\mathrm{p}$ values are expressed along with mean values and standard deviation. The $p$ values less than 0.05 were considered statistically significant.

The following biochemical parameters were estimated in both the groups.

a. Serum fluoride

b. $\quad$ Serum malondialdehyde

Serum malondialdehyde estimation (Thiobarbituric acid Reactive substance assay) Principle:

One molecule of malondialdehyde in the serum reacts with two molecules of thiobarbituric acid in acidic medium and gives rise to color complex (pink) which is measured at $532 \mathrm{~nm}$ against distilled water in a spectrophotometer.

Serum and water fluoride estimation

Ion selective electrode (Eutech fluoride electrode)

\section{RESULTS}

The present study was undertaken in the Department of Biochemistry, Kamineni Institute of Medical Sciences, Narketpally. The patients group included the postmenopausal women aged between 50 to 70 years. The control group women were in their reproductive age group, non-pregnant, healthy individuals aged between 20 to 40 years.

\begin{tabular}{|l|l|l|l|}
\hline & $\begin{array}{l}\text { Serum Malondialdehyde (MDA): } \\
\text { Controls }(\mathrm{n}=50)\end{array}$ & $\begin{array}{l}\text { Mean } \pm \text { SD } \\
\text { Patients }(\mathrm{n}=50)\end{array}$ & $\mathrm{p}$ value \\
\hline $\begin{array}{l}\text { Serum } \\
\text { malondialdehyde } \\
(\mathrm{nmol} / \mathrm{dL})\end{array}$ & $127.36 \pm 47.01$ & $287.86 \pm 49.79$ & $<0.001$ \\
\hline
\end{tabular}

Serum malondialdehyde levels were estimated by method of TBARS as an indicator of oxidative stress in both the groups. The mean values for both the groups are shown in table 4, which show the increased values in the patients when compared to that of control group. The test of significance for serum malondialdehyde between patient and control groups was statistically significant. $(\mathrm{p}<0.001)$

Serum Fluoride (F):

\begin{tabular}{|l|l|l|l|}
\hline & $\begin{array}{l}\text { Mean } \pm \text { SD } \\
\text { Controls }(\mathrm{n}=50)\end{array}$ & $\begin{array}{l}\text { Mean } \pm \text { SD } \\
\text { Patients }(\mathrm{n}=50)\end{array}$ & p value \\
\hline $\begin{array}{l}\text { Serum fluoride } \\
(\mathrm{ppm})\end{array}$ & $0.45 \pm 0.28$ & $0.68 \pm 0.39$ & $<0.005$ \\
\hline
\end{tabular}

Water fluoride from the surrounding villages of Nalgonda district $(\mathrm{n}=10)$ was estimated using Ion selective electrode, which showed the mean of $4.35 \pm 2.28 \mathrm{ppm}$. The subjects included in the study were the local residents of Nalgonda district who were exposed to the fluoride consumption for $>10$ years.

Serum fluoride levels were measured to know the fluorotic state in both case and control groups. The mean values for both the groups are shown in table 5, which shows the increased levels in the patient group. Statistical analysis shows $(\mathrm{p}<0.005)$ significant difference in patient and control group. This indicates that although both patients and controls are residing in the area of endemic fluorosis, patients had higher levels of fluoride. This could be due to difference in age.

\section{DISCUSSION}

Lipid peroxidation product, serum malondialdehyde was estimated in both the case and control group indicating the oxidative stress.

Aysel Guven et $\mathrm{al}^{6}$ conducted a study which included the assessment of the effect of chronic fluoride intoxication on lipid peroxidation by estimating serum malondialdehyde. They found that malondialdehyde levels were increased which could be associated with peroxidation of membrane phospholipids and the 
accumulation of malondialdehyde. Our study showed a statistically significant difference in malondialdehyde levels in both case and control group.

Oxidative stress is an independent risk factor for osteoporosis. ${ }^{7}$ The role of reactive oxygen species in bone metabolism is unique and dual considering their effect under physiological and pathological conditions. Under physiological conditions, the production of reactive oxygen species by osteoclasts assists in accelerating destruction of calcified tissue and hence assists in bone remodelling. Oxidative stress is able to inhibit bone cell differentiation of a preosteoblastic cell line and a marrow stromal cell line that undergoes osteoblastic differentiation. ${ }^{53}$ Enhanced osteoclastic and depressed osteoblastic activity is attributable to primary estrogen deficiency characteristic of osteoporosis. ${ }^{8}$

Oxidative stress may contribute to the development or progress of osteoporosis may indicate an underlying, or accompanying state of inflammation. ${ }^{10}$

A study by Hui Xu, Chun-hong Wang et al, has shown that, both low and high doses of fluoride caused active state of oxidative stress in osteoblasts, suggesting that oxidative stress may be excited by the active osteoblasts viability induced by a low dose of fluoride. ${ }^{11}$

Arjun L Khandare et $\mathrm{al}^{12}$ and $\mathrm{M}$ Yildiz et $\mathrm{al}^{13}$ showed that there is significant increase in the serum fluoride level in the patients with high fluoride intake. Our study shows siginificant increase in the serum fluoride in the patient group.

The serum fluoride levels of both case and control groups are low compared to that of the water fluoride levels estimated. This is because, the clearance of fluoride from plasma by the skeleton proceeds at a high rate that exceeds even for the calcium. Approximately $50 \%$ of the fluoride absorbed each day becomes associated with calcified tissues within 24 hours, while virtually all of the remainder is excreted in the urine. ${ }^{5}$

\section{CONCLUSION}

Our study showed increased serum malondialdehyde levels in case group when compared to control group indicating oxidative stress. Further studies should be done for the assessment of antioxidant status in this study group so that the adverse effects of the fluoride can be prevented by taking the necessary precautionary measures.

\section{BIBILIOGRAPHY}

[1]. Martha A. Sanchez-Rodriguez, Mirna Ruiz-Ramos, Elsa Correa Munoz. Oxidative stress as a risk factor for osteoporosis in elderly Mexicans as characterized by antioxidant enzymes. BMC Musculoskeletal Disorders. 2007; 8: $417-425$.

[2]. Dariusz Chlubek, Szczecin. Fluoride and oxidative stress. Fluoride 2003; 36217 - 228.

[3]. Flemming Nielsen, Bo Borg Mikkelsen, Jesper Bo Nielson, Helle Raun Andersen, and Philippe Grandjean. Plasma malondialdehyde as a biomarker for oxidative stress: refernce interval and effects of life style factors. Clinical Chemistry 1997; 43: $1209-1214$.

[4]. G. Banuprakash Reddy, Arjun L. Khandare, P.Yadagiri Reddy, G.Shankar Rao, and I.Srivalli. Antioxidant defence system and lipid peroxidation in patients with skeletal fluorosis and in fluoride intoxicated rabbits. Toxicological sciences 2003; 72: $363-368$.

[5]. G. M. Whitford. Intake and metabolism of fluoride. Adv Dent Res 1994; 8:5 - 14.

[6]. Aysel Guven, Necati Kaya. Effect of fluoride intoxication on lipid peroxidation and reduced glutathione in Tuj sheep. Fluoride 2005; 38(2): 139 - 142.

[7]. Meagher EA, Fitzgerald GA. Indices of lipid peroxidation in vivo: strengths and limitations. Free Radical Biol Med 2000; 28: $1745-1755$.

[8]. Gulden Baskol, Huseyin Demir, Banu Cavdaroglu, Mevlut Baskol, Derya Kocer. Assesment of paroxinase 1 activity and malondialdehyde levels in patients with osteoporosis. Erciyes Medical Journal. 2007; 29: 268 - 273.

[9]. Viereck V., Grundker C., Blaschke S., Siggelkow H., Emon G., Hofbauer LC. et al. Oxidative stress modulates osteoblastic differentiation of vascular an bone cells. Free Radical Biol Med. 2001; 31: $509-516$.

[10]. M.Akdogan, G.Eraslan, F.Gultekin, F.Sahindokuyucu, D.Essiz. Effects of fluoride on lipid peroxidation in rabbits. Fluoride.2001; 37(3): 185 - 189.

[11]. Hui Xu, Chun-hong Wang et al, Lipid peroxidation and fluorosis. Fluoride 2003; 36: 165 - 170.

[12]. Arjun L.Kandare, Rao GS, N Balakrishna. Dual x-ray abosrptiometry (DXA) study of endemic skeletal fluorosis in a village of Nalgonda district, Andhra Pradesh. Fluoride, 2007; 40(3): 190 - 197.

[13]. M.Yildiz, M.Akdogan, N.Tamer, B.Oral. Bone mineral density of the spine and femur in early postmenopausal Turkish women with endemic skeletal fluorosis. Calcif Tissue Int, 2003; 72: 689 - 693. 